\section{Treatment plans}

\section{DeAr Sirs}

There has been considerable discussion in this hospital, but no agreement, about the introduction of treatment plans for our patients. This discussion has been hampered by our ignorance of experience in other hospitals and I am therefore writing to you in the hope that this can be remedied.

I would be very interested to hear from your readers whether any hospital in this country has introduced a system for writing and monitoring treatment plans which has proved useful, practical and sustainable in the long term and which does not lead to medico-legal complications.

Broadmoor Hospital

D. TIDMARSH

Crowthorne, Berks RG11 7EG

\section{'Psychiatric Referrals from the Police' DeAr SIRS}

Rassaby and Rogers raised several important points in their article 'Psychiatric Referrals from the Police' (Bulletin, March 1987, 11, 78-81). We have recently completed a retrospective study of 240 consecutive patients who were admitted under section 136 to a psychiatric hospital in south London between January 1984 and December 1985. We should like to give further evidence in support of some of the issues raised in their article.

As in their study, we found that section 136 was being used for 'admission followed by assessment' rather than assessment followed by admission or other methods of disposal. However, as $\mathbf{7 7 \%}$ of our patients were seen after 5 p.m. or at weekends when only one social worker was oncall for the whole district, without better social work back up it would have been difficult to arrange an alternative method of disposal and still meet the requirements of the Mental Health Act 1983.

Rassaby and Rogers also pointed out that some patients who were detained under section 136 were not considered to be mentally ill. In our own study we found that $6 \%$ of our 240 patients had received no psychiatric diagnosis by the time they were discharged, a further $4 \%$ were diagnosed as having a 'situational crisis' and $12 \%$ were intoxicated with alcohol. These observations suggest that $22 \%$ of our population were not suffering from a mental illness or had a condition that is not included in the Mental Health Act 1983. Similarly the appropriateness of compulsory admission to hospital must be questioned again in the light that $23 \%$ of our population were kept in hospital for less than 72 hours.

Our study justifies the anxieties expressed in the article about the adequacy of follow-up of patients under section 136 when they are discharged from hospital. Only $39 \%$ of our population were given an out-patient appointment yet $41 \%$ were readmitted to the hospital within the two year study period.

We strongly support Rassaby and Rogers' conclusion that more appropriate facilities should be provided for the assessment of police referrals to psychiatric hospitals. The decision to admit to a psychiatric hospital should be based on clinical judgement and not on convenience, likewise follow-up arrangements should be improved and be more community based so as to come closer to meeting the needs of these people.

St Thomas' Hospital

JoHN DUNN

London SEI

The Maudsley Hospital

London SE5

(See page 224)

TOM FAHY

DeAr SIRS 'Heresy'

For less-informed journals to err in this way would be barely forgiveable; but for the same error to appear in your columns is, I believe, a near heresy. I refer to Dr Patricia A. J. Goodyear's letter (Bulletin, April 1987, 11, 133) in which her address is given as John Connolly (sic) Hospital, Birmingham.

Horton Hospital, Epsom

HenRY R. ROLLIN Emeritus Consultant

(No excuses.-Eds.)

\title{
New Publication
}

Consumers as Colleagues, by Althea and David Brandon, has recently been published by MIND. The authors have been both patients and staff in the psychiatric services and the book is based on their experience; it also draws upon workshops held with people living in a hospital and in a local authority psychiatric hostel. Copies are available from MIND Mail Order Service, 4th Floor, 24-32 Stephenson Way, London NWI $2 \mathrm{HD}$ price $£ 1.20$ (including postage and packing). 